\author{
Title Page
}

\title{
PRACTICE NURSES AS MENTORS FOR STUDENT NURSES: AN UNTAPPED EDUCATIONAL RESOURCE?
}

\section{Authors:}

Sibson, Lynda*

MSC RGN RSCN

Independent Nurse Consultant

82 Fairfield

Buntingford, Hertfordshire, SG9 9NU

Tel/Fax: 01763273242

Email: lyndasibson@btinternet.com

Machen, Ina

MA BA (Hons) RGN RHV

Senior Lecturer \& Community Link Lecturer

Department of Nursing \& Paramedic Sciences

College Lane, University of Hertfordshire

Hatfield, AL10 9AB

Tel: 01707285927

Fax: 01707285904

Email: I.Machen@herts.ac.uk

(All correspondence to Lynda Sibson)

*Evaluation undertaken whilst Senior Lecturer/Community Link Lecturer, Department of Nursing \& Paramedic Sciences, University of Hertfordshire. 


\section{Abstract}

This article describes an evaluation process aimed at exploring the issues related to placing third year undergraduate students with Practice Nurses for their adult branch community placement. The evaluation process was based on an iterative action research cycle, demonstrating a reflective approach to the placement.

This evaluation of student nurse placements with Practice Nurses intended to provide a useful contribution to the rather scant literature available on this specific issue in pre-registration nurse education. Specific outcomes from qualitative feedback revealed from both the students and Practice Nurses will be presented and compared to issues highlighted in the literature review.

The placement was evaluated highly by both students and Practice Nurses. The students enjoyed a higher than anticipated level of autonomy and were able to achieve all their learning outcomes. The Practice Nurses reported the presence of students had a positive influence on their practice. 


\title{
Practice Nurses as Mentors for Student Nurses: An untapped educational resource?
}

\begin{abstract}
$\underline{\text { INTRODUCTION }}$
Adult branch pre-registration nursing students who undertake a community placement during the branch programme are usually placed with a District Nursing team. Since 1996, at the University of Hertfordshire, a small group of $3^{\text {rd }}$ Year undergraduate adult branch students have been placed annually in GP surgeries with the Practice Nursing team. This article describes the extensive evaluation of these placements over two years (2000/2001). This evaluation had three aims, firstly to assess the effectiveness of these placements in providing relevant and appropriate learning opportunities for students; secondly to assess the value of these to the Practice Nurses and GP practices and thirdly to make recommendations for future student nurse placements with Practice Nurses as a continuing, and developing, educational opportunity.
\end{abstract}

The English National Board (ENB) \& Department of Health (DoH) clearly state that clinical areas should support the development of innovative ways of increasing and utilising practice placements, reflecting the varied communities and situations in which health care professionals work (ENB \& DoH 2001). 


\section{BACKGROUND}

At the University of Hertfordshire, students in a community branch programme placement are usually allocated a District Nurse as their Practice Mentor. As Mentors, these individuals support the student in their placement, sharing both clinical experience and theoretical knowledge. Such healthcare professionals are established, highly qualified and extremely proficient in their individual roles. District Nurses support patients with a variety of healthcare issues, delivering care in the patient's home. However these roles, whilst very valuable, offer a comparatively limited perspective of community nursing.

In 1996 it was considered that the broader perspective of primary health care could be offered to third year undergraduate students through a Practice Nurse placement. The role of the Practice Nurse, employed by GPs to deliver a range of health services, has developed rapidly over the last decade. Clinically Practice Nurses undertake a number of activities including new patient registration and over-75 year checks, aural irrigation, wound care management, family planning, cervical cytology screening, travel vaccination clinics and health promotion activities such as healthy heart clinics and chronic disease management, in particular for asthma and diabetes. A number of Practice Nurses also undertake a wider Primary Care Tutor role as well as their mentorship role for first-degree level student Practice Nurses. In addition to their educational/mentorship role, some of these Practice Nurses are currently developing roles in primary management of minor illness and injury. 
With the support of the Health Authority, some Practice Nurses Mentors were approached and the placement proposal discussed and enthusiastically accepted. The first cohort of 5 students spent their community placement with the Practice Nurses. Post placement evaluation was very positive, indicating that both the Practice Nurses and students valued the experience. The Primary Care Tutor role, that emerged post 1996, meant that the Practice Nurse Mentors were paid for this teaching role, thus facilitating acceptance of the student placements by GPs. This also ensured the Practice Nurse Mentors were highly experienced and qualified in providing a unique and educational placement experience.

Student nurses have been placed annually since 1996 with Practice Nurses in Hertfordshire. Due to time constraints, no formal placement evaluation was undertaken from the Practice Nurses perspective until 2000. Written feedback from the students has been expanded and formally collated for the past two placements. However, the very positive informal feedback led to this in-depth evaluation undertaken over two years with two student cohorts.

\section{LITERATURE REVIEW}

A 10-year retrospective literature review was undertaken to establish others' experience in this area. Anecdotally it appeared to be a unique placement and discussion with colleagues at comparable institutions did not reveal any similar examples. 
A review of English printed publications using electronic databases and a variety of search terms ("student nurse placement", "Practice Nurse (ing)") on CINAHL, British Nursing Index (BNI) and other databases revealed only one pertinent article; Carter (1997). A narrow literature search was deliberately undertaken since a specific area of nurse education was addressed in this article. Carter described an evaluative study at the University of Plymouth of adult branch diploma nursing students to establish whether Practice Nurse placements were valuable in helping students achieve their learning outcomes.

This was a small qualitative study involving a total of 19 randomly allocated students to either a 10-day Practice Nurse placement or a traditional Health Visitor placement. The aim of the study was to critically evaluate the effectiveness of a placement facilitated by a Practice Nurse and subsequent organisational time involved.

The study outcomes overwhelmingly demonstrated that the students not only found the placements appropriate for their stage in training but the Practice Nurse group progressed more consistently than the comparative Health Visitor group, specifically in relation to assessment and health promotion skills. The Practice Nurses reported some considerable rescheduling of their work in order to facilitate the student, and would have preferred a longer placement. The paper concluded that Practice Nurses were a valuable resource for nurse education, which had not been utilised to its greatest potential (Carter 1997). 
A number of research papers described various aspects of students' experiences in primary care placements. Studies included examination of student's cognitive experience (Cope et al 2000), the concept of mentorship and role of the mentor (Andrews \& Wallis 1999), education's contribution to the nursing workforce (Flanagan 1998) and the financial debate surrounding the payment of service provider for provisions of clinical placements (Lloyd Jones \& Akehurst 2000). However no other studies focused in Practice Nurse placements for pre-registration student nurses. The lack of relevant published literature suggested that there was an obvious need for further evaluation. The most pertinent article (Carter 1997) is limited for a number of reasons. Firstly the article is now 5 years old, focused on diploma level students with a 10-day placement. The author acknowledged the qualitative stance of the study limited its conclusion and there was little evidence of how placement linked specifically to the student's learning outcomes.

Similar findings were evident in this small study, e.g. significant rearranging of work schedules, relying on colleagues to cover when the Practice Nurses were unavailable and the effect of the student questioning their own practice. However, in contrast, this study was not comparative, so did not directly compare with a similar student group with other community nurses. We arguably gained more data due to the length of placement. Thus the length of the placement in this evaluation permitted an in-depth exploration of the value of these placements. 


\section{Article for Nurse Education in Practice}

\section{THE EVALUATION PROCESS}

The formal evaluation was undertaken during 2000/2001 in Hertfordshire. Seven Practice Nurses agreed to take student nurses for a 9-week placement. The Practice Nurses had previously mentored undergraduate, pre-registration students. This was an optional placement and students were free to choose a placement with a District Nurse or Practice Nurse. As places for the latter were limited, a 'first come first served' basis operated and was oversubscribed therefore not all requests could be met. During a Skills Week, prior to the placement commencing, the students were informed of the Practice Nurse option. Students informed the lecturer of their decision and names were randomly selected to ensure equity. Students not offered a Practice Nurse placement were allocated to the District Nursing Team.

Although all students had undertaken a community in their CFP programme, a specific practice preparation session was organised prior to the placement to discuss the role of the Practice Nurse, specific issues related to practice, skills that maybe observed/developed and the relationship to their learning outcomes.

With increasing pressure on the number of community placements required for both diploma and undergraduate nursing students, it was considered important that the placement was formally evaluated prior to further roll out.

Shortly before the placement, the Link Lecturers ran a Preparatory Workshop for the Practice Nurses, although not all were able to attend (those unable to attend were visited by the Link Lecturer individually). The Workshop aimed to provide an opportunity to discuss the learning outcomes, establish general communication links with the relevant Link Lecturer supporting each clinical area and to establish specific 
issues raised by the Practice Nurses to be incorporated in student placement preparation.

\section{$\underline{\text { METHOD }}$}

For the purposes of this evaluation, an action research approach was adopted. Essentially action research is a model of self-reflective inquiry undertaken in educational situations with the objective of improving rationality, justice and satisfactoriness of clinical and educational practices. Action research also aims to aid the participants' understanding of such practices, including the institutions and situations in which these practices are carried out (Kemmis 1985). Similarly ZuberSkerritt (1992) described action research as based on the fundamental concepts of action, adult learning and professional development. Since this was an evaluation of practice, based on an action research approach, no ethics committee approval was required.

Kemmis \& McTaggart's 1982 model for action research; plan, act, observe and reflect (see Figure 1) was utilised for this study. This model also mirrored Kolb's 'Model of Experiential Learning', including the cycle of reflective observation, abstract conceptualisation and active experimentation representing dynamic moments in action research (Kolb 1984).

The authors undertook the role of the Link Lecturer, both having previous Practice Nurse experience. The rationale was that relevant clinical experience was essential in not only understanding the breadth and nuances of the Practice Nurse role, but also the political nature of general practice. This facilitated credibility with the Practice Nurses whilst enabling immersion into the evaluation process, permitting 
identification of pertinent issues. This view is supported by the ENB and DoH who state that Link Lecturers should have three years full-time experience of the relevant professional practice where students will be gaining practice experience (ENB 2001).

Figure 1: Applied Action Research Model (adapted from Kemmis \& McTaggart 1992)

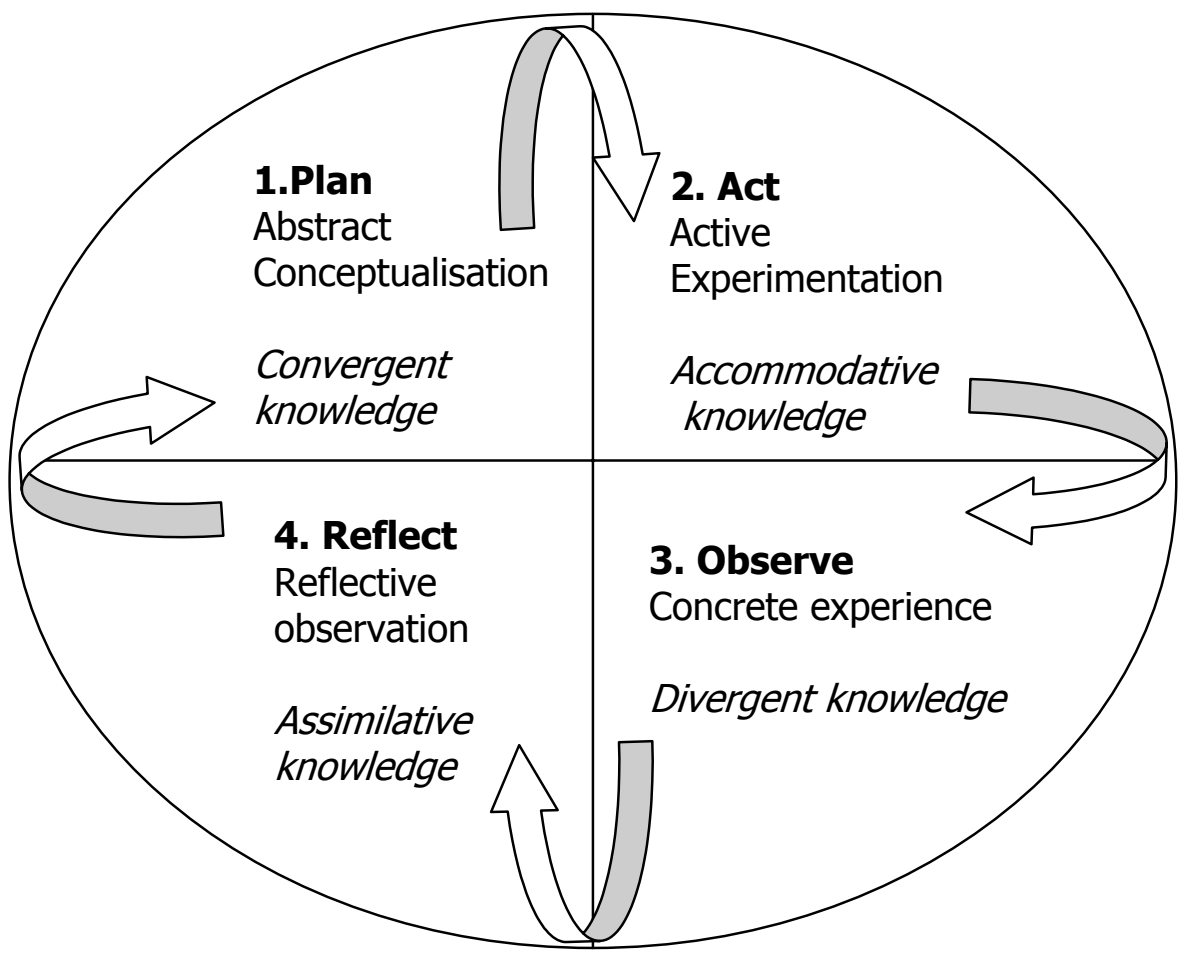




\section{EVALUATION RESULTS \& DISCUSSION}

\section{Data Collection}

Information relating to the placement was collated from short, optional, selfcompleted anonymous questionnaires. Two questionnaires were designed, one for the students and one for the Practice Nurses (see Appendix 1). Each questionnaire had a variety of question formats reflecting all aspects of the placement. The Practice Nurses received a postal questionnaire post-placement and the students completed a questionnaire on their final University day. The study results are presented as Year 1 (2000) and Year 2 (2001) unless otherwise stated. The combined response rate from students and Practice Nurses was (7) $100 \%$ in Year 1 and (6) $78.5 \%$ in Year 2. The Year 2 placement differed slightly, including one Diploma student in the cohort and a pre-placement specific session of consultation skills was included. The findings presented below discuss the evaluation of both years, highlighting similarities and differences between the two cohorts. Verbatim comments are denoted in italics.

\section{Findings}

\section{The Students' Evaluation}

The first question related to perceived overall preparation for the placement, in a Likert scale format. 


\section{Q1. Did you feel adequately prepared for the placement?}

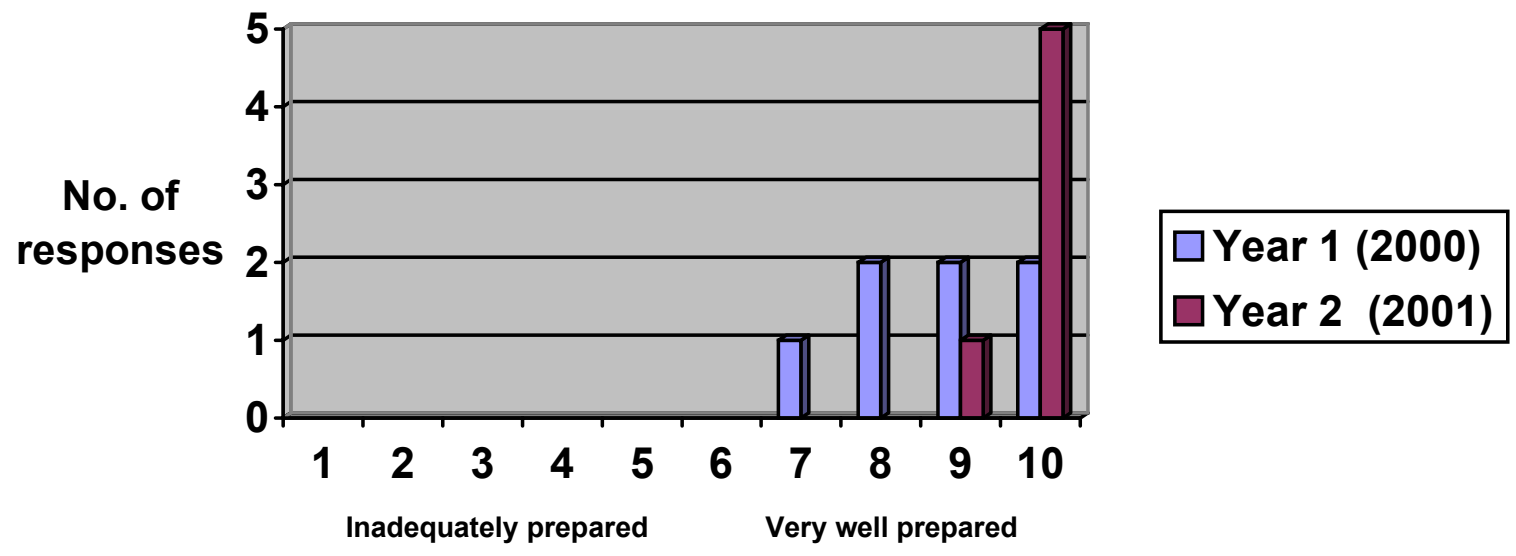

Although there was incomplete data for Year 2 (6 responses), results suggested these students appeared to feel more prepared for the placement than Year 1 ( 7 responses). This may have been a reflection of the specific Consultation Skills Workshop since this was the main area requiring development the previous year. Although not currently a formal component of undergraduate education, it was apparent from the Year 1 evaluation that the students' consultation skills needed further development. A Consultation Skills Workshop during a Skills Week was run for all students. In a two-and-a-half hour session, a PowerPoint presentation provided a theoretical overview of consultation skills, specifically related and applied to primary care, with a role-play scenario. This was a very popular and positively evaluated session.

This was a good example of the Kemmis \& McTaggart approach (see Figure 1) as an example of the main theme emerging from Year 1 (reflection); the reported lack of student's consultation skills. Intervening (plan) prior to Year 2 and developing the subsequent session on Consultation Skills proved both popular and useful (act). 
A jointly positive response from all Year 2 data (observe) has ensured future inclusion in practice preparation.

Question 2 was a free-text response option, specifying potential methods by which placements could be enhanced. Year 1 cohort suggested more information on the student nurse role in this setting, noting that wider role scoping would have been difficult to cover in preparation. In Year 2 no specific suggestions were made, although two students commented on the comprehensiveness of practice preparation.

The following question related to the role of the Link Lecturer and both cohorts reported that support from the Link Lecturer was appropriate, noted by 'timely, helpful visits; continuous availability both in person and by telephone was welcomed.

Question 4 asked students to list 3 activities they found most useful in the placement. The 3 most frequently reported activities were as follows:

1. Managing their own patient caseload and working autonomously

2. Involvement with other health care professionals

3. Refining and learning key nursing skills e.g. dressings, venepuncture

In addition Year 2 students also highlighted decision-making skills, the opportunity to integrate health promotion theory and practice and improved consultation skills.

All students reported that the learning outcomes were achievable and appropriate, with skill development integrated into the learning outcomes. 
When asked about resources utilised and support in learning the students reported utilising a wide range of resources. These included the practice Information Technology (IT) systems, the University's Learning Resource Centre, policies and procedures and observation of practice, printed and electronic literature sources of information and the Practice Nurses themselves.

Question 7 asked about support from the primary health care team. This was frequently described as 'excellent', 'brilliant' 'a very good teacher' and 'very helpful and supportive'. The students all reported that many learning opportunities were available with a number of external visits arranged. Practice Nurses also gave up some of their own time to provide additional support for achieving learning whilst encouraging independence. Similar responses were noted for the other Practice Nurses in the practice. Other members of the practice staff also provided equally high levels of support and were friendly and supportive.

Many students rated the quality of support as 'excellent', with greater than expected achievement of learning outcomes. Students almost unanimously stated that supervision as 'very high', with input decreasing as the placement progressed. This reportedly fostered independence, facilitating skill development whilst maintaining the balance of close support and distant supervision. In addition the overall quality of the learning environment was very high, with comments pertaining to the opportunity to reflect on practice, supported by the Practice Nurses' very positive approach to developing a learning environment (Question 9). Cope et al (2000) referred to this as 'cognitive apprentice', whereby the expert 
makes their knowledge explicit, withdrawing support as they transfer these skills to the learner. Additionally Carter (1997) noted in her study that the Practice Nurses, all Primary Care Tutors, were experienced and qualified in student facilitation, highlighting a previously unmet need.

These qualities were reflected in response to Question 10, noting which aspects the students most enjoyed about the placement. Other aspects included developing autonomy, responsibility of managing a small patient load with indirect supervision and being part of a team. The fact that the Practice Nurses were up-to-date on current practice was welcomed.

Negative aspects of the placement related to financial issues (having to initially pay travel expenses), situational (overheated treatment rooms) and clinical (child immunisation clinics and consulting with patients with little preparation-although no example was provided). No suggestions were put forward for improvements. The long working hours were considered negatively. Students felt they worked very hard since many of the Practice Nurses ran clinics out of office hours to meet patient demand and some students had considerable travelling distances to home. These negative aspects were practical and difficult to overcome in the short term.

In relation to potentially enhancing future student placements, greater protected time for reflection would have been an advantage. Generally the rule for other placements is approximately one hour per day set aside for reflection. 
Additional comments suggested that the placement was unanimously enjoyed and was very popular with the students. Free text comments revealed a high level of satisfaction; particularly in relation to the student management of their own caseload. This aspect of autonomy was greatly appreciated and facilitated development of their communication and consultation skills. Students reported that the placement provided a wealth of both academic and clinical learning opportunities and allowed the students to consolidate their skills, largely gained through observation, active participation and discussions with the health care staff. Being a viewed as a 'team member'was also a strong theme, witnessed by the Link Lecturers during their visits. Interestingly no suggestions for any changes/improvements were given.

The Practice Nurse Evaluation

\section{Q1: Did you feel the student was adequately prepared for the placement?}

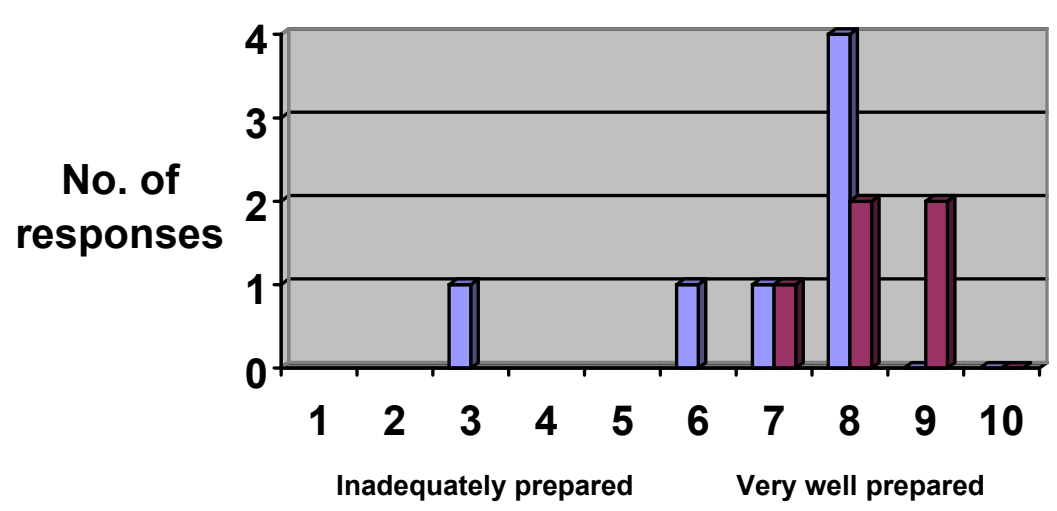

$\square$ Year 1 (2000)

$\square$ Year 2 (2001)

Although there was a lower response rate in Year 2 (6), there was a higher overall score for the perceived preparedness of students.

Question 2 referring to the main areas for placement improvement in Year 1 (7 responses) included a higher level of student's clinical skills e.g. administration of injections $\&$ aseptic technique. This was perceived as lacking by almost all the 
Practice Nurses. In addition communication and consultation skills were also considered an area for improvement. In Year 2, the Practice Nurses felt that the students were better skilled, with the placement developing existing skills rather than teaching new ones.

Practice Nurses reported the Link Lecturer provided good support, responses ranging from 'excellent/very good' to 'adequate'. Maintaining availability whilst keeping a low profile appeared to be appreciated. Both students and Practice Nurses considered the role of the Link Lecturer valuable. However there was greater variation of responses by the Practice Nurses, although the specific reasons were not documented. The face-to-face and distant model of support, i.e. available by telephone was accessed more by the students than Practice Nurses. One visit per placement was arranged, with subsequent visits as required.

The most useful activities for the students during the placement, from the Practice Nurses perspective, included clinical and practical skills such as health promotion, screening, venepuncture, aural irrigation, wound care management, consultation \& communication skills and computer literacy were most notable. The development of autonomy and one-to-one supervision were considered valuable. Team working, undertaking some management skills and home visiting were also reported as useful activities.

The Practice Nurses stated that the student's learning outcomes appeared relevant, useful, and appropriate for the placement. However, it was considered difficult for the both the students to demonstrate and the Practice Nurses to assess 'leadership 
qualities', largely due to lack of an additional comparatively junior student in placement. It was felt that achievement of all the learning outcomes in the placement timeframe was a 'tall order'.

Question 6 related to the utilisation of resources to achieve learning outcomes, which appeared to be accessed and well utilised, some larger practises having a small library/resource centre.

Regarding additional support, in Year 1 this was available from other Practice Nurses, particularly useful for those Practice Nurses working part-time. Future recommendations included a suggested list of visits e.g. coroner's court, undertaker and local schools. This was developed for Year 2. Year 2 respondents regarding any support made no examples or comments necessary for future placements.

Suggestions for enhancing the placement included students' attendance at case conferences rather than emphasis on more traditional visits. More protected time spent on one-to-one supervision with the student would have addressed some apparent disjointed knowledge on disease management theory and practical skills. Other suggestions included more teaching of IT skills for the Practice Nurses.

Very positive responses were made to Question 9 regarding benefits to the Practice Nurse of student mentorship. Comments included 'it made me think!' 'a breath of fresh air for all team members', 'patients liked a young face'. The opportunity to teach was welcomed, not only to appreciate current nurse education but also selfreflection, facilitating verification of evidence-based practice. Carter (1997) reported 
this benefit of the provision of on-going learning whilst questioning skills and expertise; a 'mutual reflective process'. The inclusion of a student within the team was noted to benefit team building, stimulated discussion and facilitated evaluation of practice working. The student placement provided a learning opportunity for all staff, which enjoyed a team member who was motivated and enthusiastic. This resulted in the promotion of a 'learning environment'. The opportunity for the Practice Nurses to question their own practice was also important. The term '/earning environment'was used to reflect this concept, since it appeared to impact on all members of the primary health care team, from GP to receptionist. Andrews \& Wallis (1999) observed that whilst students recount positive accounts of their mentor, benefits to mentors themselves are often intrinsic; examples include personal satisfaction of watching their mentee progress.

Other perceived practice benefits included students quickly became valued team members, not only providing an 'extra pair of hands'for skills such as phlebotomy but sharing experiences and challenging the practice staff who enjoyed observing the development of a motivated individual. The 'prestige' of links with the University and being viewed as a training practice were also seen as positive outcomes.

Commonly reported negative aspects were largely the pressures on time, although this was mainly in the early days of the placement. This related to the organisation of proxy supervision when the Practice Nurse was unavailable and the lack of protected time to discuss individual patients. 
Responses to Question 12 regarding practical disadvantages included the increased time required for the Practice Nurses and lack of space for the students. The most significant barrier to further diffusion of this placement is financial. Currently GPs do not receive any payment for offering placements to student nurses. This issue was the largest negative aspect, the financial and time cost to the practice. From this evaluation, the GPs reportedly felt strongly that a financial payment in recognition of the services provided should be made. Carter (1997) revealed similar issues and a one-off payment was made to GPs. However Lloyd Jones \& Akehurst (2000) discussed this issue at length, summarising that this was an unnecessary contractual procedure, causing potential inequity since there was no evidence to support payments to placements in the acute sector. Financial reimbursement is provided for medical student placements therefore it appears inequitable that a similar process is not implemented for nurse education; although as Lloyd Jones \& Akehurst (2000) comment, nursing students do make a contribution to patient care. It could be argued, therefore, that this service contribution compensates for the extra time required by the Practice Nurses for their mentorship role.

Finally the Practice Nurses were asked whether they believed that the student placements should be further developed in other GP practices. The overwhelming response was 'yes'. Respondents expressed the view that the placement provided excellent all round experience for students, they gained an enormous amount of knowledge during the placement and hoped this would encourage younger nurses to come into general practice, important for future recruitment. Careful selection of practices was also necessary to ensure that the students' needs may be met. 
The Practice Nurses spontaneously reported that they positively enjoyed mentoring a student and would be happy to supervise future students. The breadth of experience that the Practice Nurses could offer was valuable, particularly at this stage in training. Protected time for reflection was deemed an essential requirement. However these senior students were viewed as providing a valuable resource to the practice, assisting with a heavy workload, contributing to practice, e.g. sharing IT skills, developing health promotion leaflets.

\section{QUALITATIVE DATA ANALYSIS}

Data was collected using specifically designed questionnaires. Since this was a small evaluation, issues emerging from the open-ended questions were categorised simply into groups and refined during the evaluation process until a number of key issues were evident.

\section{EMERGING ISSUES}

Despite being a small-scale evaluation, a number of applicable issues emerged from the evaluation. The concept of autonomy appeared highly valued by students, reportedly assisting confidence development, underpinning both new and previously acquired skill development. Year 2's enhanced decision-making and consultation skills were possibly a result of the Skill Session, and noted by the Practice Nurses in Year 2. Cope et al (2000) also commented that the key to developing such skills is the authentic context in which they are practiced. This issue of skills enhancement was also noted as a positive factor in Carter's (1997) study. 


\section{Article for Nurse Education in Practice}

Issues of time were also relevant for the Practice Nurses who found the initial impact of a student time-consuming. Carter (1997) reported a similar issue with time management, with $50 \%$ of the Practice Nurses finding that the facilitation process taking longer than anticipated. The students evidently gained much experience and knowledge during the placement and in conjunction with a long, busy day found it difficult to assimilate this new and emerging knowledge.

All Practice Nurses had a number of other roles and were not with the students continuously. Benefits for the practice were largely practical, the 'extra pair of hands', although this was not taken advantage of and the experience facilitated the student's skill development. Such benefits tend to be qualitative, however students often incur cost, particularly in primary care where time is the greatest resource provided by highly qualified staff.

\section{CONCLUSION}

Overall the evaluation was very positive. The increased academic nature of nursing courses has been criticised for the theoretical predominance at the cost of basic practical, clinical skills such as blood pressure monitoring and wound dressing, influencing future nursing practice (Flanagan 1998). Whilst it was not possible to address this specific issue in this evaluation, the issues of communication and consultation skills were addressed, particularly as both students and Practice Nurses raised this as an educational need. 
Until recently the ENB $997 / 998$ qualification was required by all registered nurses acting as Assessors/Mentors. From September 2001 the nursing regulatory board, in conjunction with the DoH has implemented a new assessment qualification for all Teachers and Mentors. Those individuals with the ENB 997/998, such as the Practice Nurses, will be able to continue acting as Mentors with no further training required apart from mentor updating session as organised by individual HE providers.

Study limitations were mainly associated to sample size. This article contributes to the limited published literature currently available regarding student nurse placement with Practice Nurses. Similar larger research studies would need to be undertaken in order to address some of the methodological issues.

In summary, this study has explored a potentially untapped resource of valuable undergraduate nurse education. The evaluation demonstrated that the placement provides an opportunity for senior students to experience a holistic and varying perspective of primary health care, arguably the future of health care delivery in the UK. The placement benefited not only student and Mentor, but also the entire primary health care team. Exposure to such a rich learning environment may also encourage higher levels of recruitment and retention into this valuable role for the future. 


\section{ACKNOWLDGEMENTS}

The authors wish to acknowledge the considerable time and effort from the Practice Nurses in their role as student mentors and the high quality of placement supervision. In additon we wish to thank the students for their valuable feedback and hard work during the placement. 


\section{References}

Andrews M \& Wallis M 1999 Mentorship in nursing: a literature review. Journal of Advanced Nursing. 29 (1) 201-207.

Department of Health \& ENB 2001 Preparation of Mentors and Teachers: A new framework of guidance. Luton: Chiltern Press.

Carter R 1997 Practice Nurses: Facilitators of learning? Practice Nursing. Vol 8 No 19 14-16.

Cope P, Cuthbertson P \& Stoddart B 2000 Situated learning in the practice placement. Journal of Advanced Nursing. 31 (4) 850-856.

Flanagan J 1998 Achieving partnership: the contribution of nursing education to the production of a flexible workforce. Journal of Nursing Management. 6 129-135.

Kemmis S 1985 Chapter 10: Action research and the politics of reflection. IN Boud D \& Keogh R 1985 (eds) Reflection: turning experience into learning. London: Kogan Page Ltd.

Kemmis S \& McTaggart 1982 The Action Research Planner. IN Zuber-Skerritt O 1992 Professional Development on Higher Education. London: Kogan Page Ltd

Kolb D 1984 Experiential learning: experience as the source of learning and development. London: Prentice-Hall.

Lloyd Jones M \& Akehurst R 2000 Should service providers be paid for providing pre-registration clinical placements? Journal of Advanced Nursing. 32 (2) 432-436.

Zuber-Skerritt O 1992 Professional Development in Higher Education. London: Kogan Page Ltd. 
APPENDIX 1

Practice Nurse Evaluation Questionnaire

(This may be replicated following permission of the authors) 


\title{
University of Hertfordshire Faculty of Health \& Human Sciences
}

\section{Department of Nursing \& Paramedic Sciences}

\author{
BSc (Hons) Nursing \& Registered Nurse Clinical Placements \\ in Practice Nurse Settings
}

\section{Practice Nurse Evaluation Questionnaire}

the aim of this questionnaire is to explore your experiences \& views following the recent placement of a $3^{\text {rd }}$ year degree/diploma student nurse in your practice. as evaluation is an important element of clinical practice, we would appreciate comments from your perspective of the placement. all comments will be in confidence.

\section{Placement Preparation}

1. Did you feel that the student was adequately prepared for the placement?

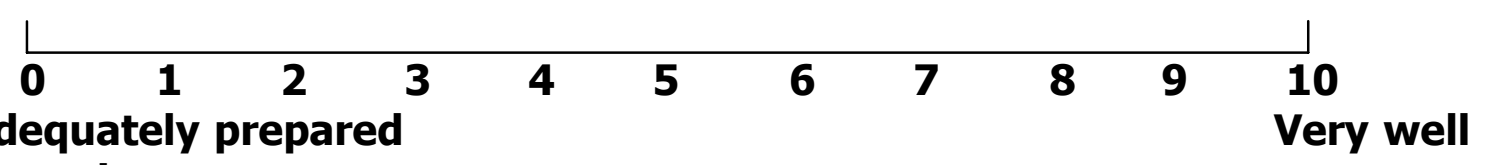

Inadequately prepared prepared

2. Are there any ways in which the practice preparation could have been enhanced?

3. Please comment on the support that the Link Lecturer provided during the placement. 


\section{PLACEMENT EXPERIENCE}

4. Which activities did you feel were most useful in this placement for the student?

5. Please comment on the appropriateness of the learning outcomes for the placement.

6. Did you think that the student had access to appropriate resources/assistance to achieve these learning outcomes?

SUPPORT/SUPERVISION

7. Was there any further support you required to facilitate the student's placement?

8. Can you suggest any ways in which the placement could have been enhanced? 
9. Were there any benefits to you during the placement? If yes, please outline.

10. Were there any disadvantages for you during the placement? If yes, please outline.

11. Were there any benefits to the practice in providing this placement?

12. Were there any disadvantages to the practice in providing this placement?

13. Do you think that the placement of Student Nurses with Practice Nurses as part of their community experience should be further developed with other GP practices \& students? Please explain your rationale. 


\section{Additional Comments}

Finally, if you have any additional comments you would like to make about your experiences as a Practice Supervisor, please write them in the space below. Please continue on the reverse of this sheet or use another sheet if necessary.

Thank you for taking the time to complete the evaluation. your comments are valuable and will be treated in confidence. 